\title{
Mário de Andrade: corpo e imagem. Trajetória das representações do intelectual modernista
}

\author{
Rosa Veloso Dias Giannaccini
}

\begin{abstract}
Resumo
Este ensaio investiga o percurso das representações do intelectual Mário de Andrade: como elas foram sendo elaboradas ao longo da vida do escritor, expandidas após a sua morte, conservadas e renovadas no meio cultural brasileiro. Analiso as representações iconográficas, a obra poética e ficcional, os depoimentos e entrevistas, a produção epistolar e a recepção crítica. Os filósofos Maurice Merleau-Ponty e Henri Bergson, que exploram conceitualmente o corpo e a imagem, fundamentam a pesquisa.
\end{abstract}

Palavras-chave: Mário de Andrade. Modernismo. Corpo. Imagem.

A imagem se impõe como o modo essencial da relação entre os seres e o mundo, especialmente quando se pensa que todo indivíduo é levado a se mostrar e a produzir uma imagem de si mesmo. No jogo entre a consagração e o desaparecimento, percebe-se como alguém deseja sobreviver após a sua morte, gerando imagens que garantirão a sua perpetuidade. Nesse conjunto de representações, as manifestações corporais suscitam diversas interpretações e se transformam em campo de pesquisa inesgotável ao promover a aplicação de estudos interdisciplinares e ao redimensionar a leitura do corpo traduzido como objeto e que só pode ser captado pelo instigante universo do imaginário. Provocam, ainda, reflexões sobre a imagem provisória, inacabada e efêmera da corporalidade na cultura contemporânea.

A conceituação de imagem e os múltiplos empregos que esse termo suscita permitem ao pesquisador eleger a noção mais adequada aos objetivos de sua investigação. No estudo da trajetória das imagens do intelectual Mário de Andrade, o conceito de imagem - entendida como certa unidade de significação cultural derivada de representações de um sujeito - vai além do sentido restrito da representação visual do escritor e da sua posição de intelectual, e se expande até uma significação mais ampla, ao incorporar certo número de qualidades sócio-culturalmente elaboradas.

As imagens de Mário de Andrade foram sendo construídas ao longo da vida do poeta. No entanto, mesmo após sua morte, continuaram a ser geradas, contribuindo, de modo significativo, para ampliar o acervo de representações do intelectual. Em sua trajetória, essas imagens desenham-se em círculos concêntricos, que vão se expandindo, mas não se excluem, enquanto os arranjos vão se transformando e os 
registros interagindo ao longo do tempo. Inicialmente, as imagens apresentam-se em esferas mais estritas, na reprodução mais imediata do corpo, em suas representações iconográficas, nas quais se destaca o rosto, nos retratos pintados ou nas fotos, momento do qual participa diretamente o próprio Mário de Andrade. Depois, aparecem construídas pela crítica, com o suporte material da obra, contribuindo para o fortalecimento de sua imagem pública e a conseqüente valorização como escritor modernista. Em seguida, são produzidas a partir do movimento de recepção de Mário após a sua morte, com a publicação gradativa da obra póstuma e da correspondência completa, das quais novas leituras e releituras permitem o sucessivo aparecimento de mais imagens públicas do escritor, atestando o alcance de sua influência a vários domínios da cultura brasileira. Posteriormente, as representações escultóricas revelam a estratégia para a consolidação da imagem em espaços públicos, nos quais se entroniza o nome de Mário de Andrade, que ganha conotações específicas, alcançando um sentido mais amplo, adquirindo um valor cultural pelo papel que desempenha na cultura brasileira. Finalmente, resultam do movimento de releitura, da obra e de sua imagem pessoal, que produz novas figurações, ampliando o espaço de reflexão e compreensão do intelectual modernista.

As imagens que surgem dos textos selecionados, reunidas em determinados conjuntos, são indicadoras do percurso do escritor como figura notoriamente pública, em contraste com outras reveladoras do lado íntimo de sua vida privada. Assim, ordenadas ao longo da pesquisa, elegendo-se o corpo como leitmotiv/motivo condutor, essas imagens constituem um valioso instrumento para se conhecer Mário de Andrade, pois fornecem informações sobre objetos, lugares e sua própria pessoa, modos de o escritor se relacionar com o mundo concreto que o rodeia.

A escolha do eixo corpo-imagem como espaço de pesquisa deve-se à importância de demarcar limites, evitar a dispersão e conseguir o necessário rigor na análise do imenso texto que é a obra de Mário de Andrade. Por um lado, a imagem é um meio de expressão e de comunicação que se vincula às tradições mais antigas da cultura. A sua leitura, enriquecida pelo esforço da análise, torna-se um momento privilegiado para o exercício da crítica, especialmente pela representação visual na qual ela se inscreve; permite, ainda, compreender melhor um dos instrumentos efetivamente predominantes na comunicação contemporânea. Por outro lado, a reflexão acerca do corpo, hoje colocado no centro de questionamentos instigantes, sempre atraiu pesquisadores que exploram com olhar crítico os limites do indivíduo e suas fronteiras reais e imaginárias.

A opção da linha teórica que orienta esta investigação permite observar como se elaboraram certas imagens de Mário de Andrade, e até que ponto o corpo pode ter produzido interferências nessa construção. Constata-se uma multiplicidade de imagens corporais que atestam a impossibilidade de se captar uma única realidade do corpo e evidenciam sua virtualidade, já que o corpo não cessa de se manifestar na transitoriedade de tais imagens. Entre tantos teóricos voltados para o estudo do corpo e da imagem, destacam-se os filósofos Maurice Merleau-Ponty e Henri Bergson, que analisam o corpo e a imagem segundo uma perspectiva fenomenológica, já que ambos os conceitos podem ser entendidos como elementos de uma estrutura existencial que decorre imediatamente da relação corpo-mundo.

A Fenomenologia da percepção, de Maurice Merleau-Ponty, é a procura de uma filosofia que adota o corpo, o espaço, o tempo e o mundo como categorias fundamentais de sua investigação. Em Matéria e memória, Henri Bergson se deteve no problema tradicional das relações entre o corpo e a alma e na explicação do 
conhecimento intuitivo, faculdade que une o sujeito ao objeto. Muitas dessas formulações de caráter geral convergem para uma área de encontro das filosofias da vida, da fenomenologia e das correntes existenciais que visavam reaproximar a filosofia da existência concreta do ser humano com a valorização da consciência perceptiva, indispensável a essa existência concreta, preocupações que garantem atualidade a esses dois pensadores.

Merleau-Ponty parte de questões básicas - mundo vivido, percepção, visibilidade - para desenvolver o corpo como constructo. Articula os conceitos duplos: ver-ser visto, sentir-sentido, tocar-tocado; desse modo o corpo não está situado no mundo apenas como objeto, nem apenas como sujeito, mas está entre os dois, por isso é corpo-sujeito, modo de ser do corpo de se manifestar no mundo. Para o filósofo, a partir da percepção, na experiência da própria existência através do corpo, é que se realizam as relações entre o corpo e as coisas exteriores. Assim, o sujeito está situado no espaço e no tempo e enraizado no mundo com seu corpo, porque é como corpo que se relaciona com o outro, que percebe o outro porque o outro é percebido. Ter um corpo que percebe, que vê, que sente é ter a capacidade de captar e exprimir significativamente aquilo que se manifesta no mundo; é a maneira que se tem de ter acesso ao mundo.

A força da análise de Bergson sustenta-se na relação que estabelece entre ação e representação e na ligação entre o que chama de reconhecimento e sobrevivência das imagens. Depreende-se a imagem, para Bergson, como uma série de representações que operam na memória e que são diretamente manifestas no corpo, que, por sua vez, não passa também de uma imagem. Ao acionar a memória, evocam-se todas as percepções passadas a uma percepção presente, e é pelo corpo, com seus centros perceptivos estimulados, que se tem a representação das coisas. Por outro lado, o papel desses estímulos é unicamente esboçar as ações virtuais, preparar as reações do corpo sobre os corpos circundantes. A percepção, portanto, consiste em separar, do conjunto dos objetos, a ação possível do corpo sobre eles; permite selecionar as imagens que interessam à imagem que se chama corpo.

Nesse mundo de imagens, o corpo também é uma imagem e, no momento em que aumento ou diminuo a percepção dessas imagens, o corpo se transforma na imagem por excelência, prevalecendo sobre todas as outras. Entretanto, as imagens são percebidas como fragmentos de um corpo que é, antes de tudo, um corpo imaginário, ou seja, tudo nele se desenvolve a partir da imagem que determinada cultura faz dele. Assim cada cultura, a partir de sua especificidade, fabrica um corpo próprio quando se dá a interação entre a sensibilidade e o meio em que se encontra. Entendendo-se a percepção como a ação virtual das coisas sobre o corpo e do corpo sobre as coisas, haverá sempre, em toda percepção, algo do corpo quando o desenho dessa ação virtual se transforma em ação real e é percebida pelo corpo. Assim, a ação real é sentida e está no corpo, e a ação virtual, percebida como imagem, fora do corpo. Sinto com o corpo e construo imagens fora do corpo. E, por isso, esse corpo se manifesta ao mesmo tempo na forma de sensação e na forma de imagem. Daí resulta o paradoxo que cerca o corpo: é uma imagem entre tantas outras imagens, recebendo e devolvendo movimento, mas mantém seu centro de ação como uma imagem constante embora não completa, exercendo sobre as outras imagens uma influência real, escolhendo a maneira de devolver o que recebe.

O corpo, porém, não é apenas uma imagem; ele se manifesta também do ponto de vista fenomenal, pois, como observou Merleau-Ponty, não é nunca o corpo objetivo que se move, mas o corpo fenomenal, ou seja, antes de qualquer intenção objetiva o 
corpo já é potência à ação. Desse modo, o filósofo resume a diferença entre corpo objetivo e corpo vivido, que coexistem num mesmo mundo: não estou diante de meu corpo, estou dentro de meu corpo, ou, mais certamente, sou o meu corpo. As suas análises preocupam-se com o "mundo da vida", análises cujos elementos passam pelo corpo, nosso "ancoradouro do mundo", lugar que tem a sua expressividade própria, meio articulador das primeiras e fundamentais significações. É nesse sentido que a existência é corporal; é, portanto, na "experiência vivida" ou na "existência" que se pode apreender a complexa trama do comportamento humano. E, por sua vez, a "experiência vivida" funda-se no ato perceptivo, campo privilegiado do entrelaçamento corpo-mundo.

Como diante de um espelho, o corpo pode ser visto como um objeto, admitindose um desdobramento do sujeito em observador e observado. O permanente desdobramento do corpo em um outro é a raiz de sua ambigüidade original, faz dele um horizonte aberto às percepções e o impede de estar plenamente constituído. Para Merleau-Ponty, cada um de nós traz o outro, o mundo, o cultural, o social, o corpo e a linguagem formando um nó inextricável. É essa imagem complexa de uma realidade inconclusa, na qual as contradições existem, mas não se resolvem pelo pensamento, o centro da concepção de Merleau-Ponty, cuja teoria permite analisar e, ao mesmo tempo, ajuda a compreender a existência ambígua, exposta na escrita inacabada da obra do escritor Mário de Andrade.

Para investigar as imagens de Mário de Andrade, é preciso recorrer à sua obra poética e ficcional, transitar por seus depoimentos e entrevistas, desvelar o entrelaçamento entre carta e crítica, procurar entender seu pensamento encerrado na correspondência enquanto testemunho e memória. No grande painel da epistolografia, revelam-se tensões e contradições experimentadas pelo escritor em nuances resguardadas pela escrita profundamente pessoal, cujo traço de oralidade irrompe para dar-Ihe o tom de controvertida expressão lingüística. Em Mário de Andrade, carta, testemunho, ficção, biografia ligam-se estreitamente, compondo um texto complexo e estimulante para os pesquisadores de sua obra.

Naturalmente, a crítica produziu imagens do intelectual. Entretanto, no espaço das cartas e nas respostas de seus interlocutores é que se pode observar melhor como se deu a construção e a recepção das imagens de Mário de Andrade, como se mostrou a si mesmo e aos outros, pois as cartas devolvem novas imagens, às vezes contraditórias, do escritor. Os textos das cartas de Mário de Andrade apresentam uma estrutura intrincada, cujos assuntos e temas, quase sempre em idas e vindas, aparecem de modo recorrente em diversos destinatários. As imagens se constroem obedecendo a determinados ritmos, manifestando-se simultaneamente, sem que uma anule a outra, não se constituindo de modo homogêneo. Portanto, julgo necessário contextualizar a sua produção literária e epistolar para possibilitar uma ordenação mais metódica desse universo caleidoscópico de imagens.

A obra de Mário de Andrade, marcada pelos conflitos próprios à natureza humana, é plena de questionamentos que instigam o leitor a acompanhar as contradições de um corpo voltado ao mundo. Embora a partir de seus textos seja possível tratar de inúmeras questões literárias e culturais importantes, algumas estão mais intrinsecamente vinculadas entre si, como: a relação entre vida e obra; o traço autobiográfico presente nos textos ficcionais; o fingimento versus a sinceridade; a amizade literária; o papel do intelectual; o engajamento político do artista; o sujeitoator que, de modo ambíguo, se exibe indistintamente nos espaços da vida privada e da vida pública; temas abordados com freqüência pela crítica literária contemporânea. 
Os registros iconográficos - imagens surgidas no meio literário e cultural brasileiro, no momento em que Mário despontou como escritor - mostram não só as primeiras revelações da imagem pública do intelectual como a imagem privada do homem, que despontou do convívio pessoal, em meio aos conflitos inerentes a essa descoberta de si mesmo e como escritor. Tais representações manifestam-se em variados suportes, tais como fotos, pinturas e caricaturas, e permitem elaborar análises das relações que o escritor estabelece com artistas plásticos de sua geração, não medindo esforços para projetar-se como intelectual no meio paulistano. Desse modo, abre-se um espaço para se pensar no corpo como um objeto e nas várias formas de como se pode representá-lo, formas que traduzem um modo de ser no mundo, como se o corpo não fosse nada sem o sujeito que o habita. Investigo também o corpo de Mário em relação à sua espacialidade, fator importante para se afirmar como sujeito, paulista e brasileiro. O escritor rompe a fronteira do corpo, que separa o indivíduo do resto do mundo, separa o "eu" do exterior; mostra-se no traje que dissimula, realça o que deseja mostrar ou se esconde. Projeta-se em diversos espaços, desde a intimidade de seu quarto, de sua casa, que afasta a vida privada da vida social, distancia o "meu" do coletivo, e aparta o pequeno grupo privado, a família nuclear - o "nosso" - da multidão anônima no espaço público, até o mais distante fisicamente, porém próximo culturalmente: o continente europeu. Na produção escrita, evidenciam-se certas relações entre o corpo e traços peculiares da identidade de Mário, representados por referências à infância, aos familiares, às ligações afetivas, ao ser metassexual, revelador de uma sexualidade presente em toda parte e em nenhum lugar, a qual, sem poder especificar, torna-se, portanto, ambígua.

A produção de imagens de Mário de Andrade contribuiu também para consolidar sua imagem pública, em um segundo momento de sua trajetória intelectual, momento em que se avolumou a correspondência a partir do número crescente de amigos do mundo literário e o contato com artistas plásticos famosos, que vão ajudá-lo na construção dessas representações. Por outro lado, à medida que aumenta a exposição da figura pública, sua imagem sofre cada vez mais interferências da crítica, fato que repercute não apenas no corpo, como nas relações e manifestações de sua vida privada, e traz profundas conseqüências para a sua vida pública e intelectual. Algumas imagens foram sendo elaboradas paralelamente pelo escritor, a partir da sua obsessão pelo trabalho, inclusive de funcionário público, a decepção que resultou dessa progressiva exposição pública e inevitável confronto com certas escolhas políticas, e a opção por retornar ao "seu" mundo privado, com a conseqüente reflexão sobre os limites do indivíduo diante das pressões sociais.

As imagens de Mário subsistem mesmo quando seu corpo já não mais existe, e preservam a natureza ambivalente. A geração de imagens de Mário de Andrade em um contexto cultural mais recente, em face de um consistente parque gráfico e editorial brasileiro, e de novos meios de comunicação, indica que, culturalmente, há necessidade de se criar imagens para atender a uma demanda social. Na esfera pública, surgem novas imagens do intelectual, seja através de monumentos, do nome consagrado nos espaços públicos e propagando-se pela mídia. Constata-se a reinscrição do escritor no discurso crítico contemporâneo e a percepção de estar inserido progressivamente no cânone literário brasileiro. Divisa-se o movimento de retomada e releitura das imagens de Mário de Andrade, ao lado de tentativas que procuram valorizar certos atributos reconhecidamente identificados por ele $\mathrm{e}$ sustentados em sua obra literária. 
$\mathrm{Na}$ ambigüidade irredutível da imagem de Mário, reside o aspecto mais fascinante das interpretações provocadas pela dinâmica das representações do corpo. Do primado do corpo imortalizado na arte, do escritor petrificado no mito, às representações que irrompem livremente no espaço cultural brasileiro, nesse fluxo de tensões e deslocamentos oscila a imagem do intelectual Mário de Andrade. Este ensaio também elabora uma imagem de Mário: a imagem de um percurso.

Abstract

This essay investigates the path of representations of the intellectual Mário de Andrade: how they were constructed throughout the writer's life and expanded after his death, preserved and renewed in the Brazilian cultural environment. I analyze the iconographic representations; I research the poetic and fictional oeuvre, as well as interviews, recorded statements and letters. The philosophers Maurice Merleau-Ponty and Henri Bergson, who conceptually explore the body and the image, are further support for the research.

Key words: Mário de Andrade. Modernism. Image. Body.

\section{Referências}

ANDRADE, Mário de; ANDRADE, Carlos Drummond de. Carlos \& Mário. Correspondência de Carlos Drummond de Andrade e Mário de Andrade. Rio de Janeiro: Bem-te-vi, 2002.

ANDRADE, Mário de; BANDEIRA, Manuel. Correspondência Mário de Andrade \& Manuel Bandeira. São Paulo: EDUSP/IEB, 2000.

AUMONT, Jacques. A imagem. Campinas: Papirus, 1993.

BARTHES, Roland. A câmara clara. Rio de Janeiro: Nova Fronteira, 1984.

BERGSON, Henri. Matéria e memória. São Paulo: Martins Fontes, 1999.

JEUDY, Henri-Pierre. O corpo como objeto de arte. São Paulo: Estação Liberdade, 2002.

JOLY, Martine. Introdução à análise da imagem. Campinas: Papirus, 1996.

MERLEAU-PONTY, Maurice. Fenomenologia da percepção. São Paulo: Freitas Bastos, 1971.

MICELI, Sergio. Nacional estrangeiro: história social e cultural do modernismo artístico em São Paulo. São Paulo: Companhia das Letras, 2003. 